\title{
Differences in spatio-temporal parameters between trained runners and untrained participants
}

Running title: Differences between trained runners versus untrained

Laboratory of Physiology and Biomechanics. University of the Basque Country.

Full Names of the Authors:

Josué Gómez-Molina ${ }^{1}$, Ana Ogueta-Alday ${ }^{1}$, Christopher Stickley ${ }^{2}$, Jesus Camara Tobalina ${ }^{1}$, Jon Cabrejas-Ugartondo ${ }^{3}$, Juan García-López ${ }^{4}$

Institutional/Corporate Affiliations:

${ }^{1}$ Faculty of Education and Sport, University of the Basque Country, UPV/EHU, Vitoria-Gasteiz, Spain.

${ }^{2}$ Department of Kinesiology and Rehabilitation Science, College of Education, University of Hawaii at Manoa, Honolulu, HI, USA.

${ }^{3}$ Hospital Comarcal Santiago Apóstol. Miranda de Ebro. SACYL.

${ }^{4}$ Department of Physical Education and Sports, Institute of Biomedicine (IBIOMED), University of León, León, Spain.

Contact Details for the Corresponding Author:

Josué Gomez-Molina

Faculty of Education and Sport, University of the Basque Country, UPV/EHU, Lasarte 71, 01007, Vitoria-Gasteiz, Spain. Telephone number: 945013500

E-mail address: josue.gomez@ehu.es 


\section{Funding}

This work was supported by the Basque Country Government under a predoctoral grant number reference PRE_2013_1_1109.

\section{Abstract}

The aim of this study was to compare the spatio-temporal parameters of trained runners and untrained participants with the same foot strike pattern (rearfoot) during running at controlled speeds. Twenty-one participants were classified in two groups according to their training experience: Trained $(n=10$, amateur runners with long distance training experience) and Untrained ( $\mathrm{n}=11$, healthy non-trained participants). Anthropometric variables were recorded, and the participants performed both a submaximal (between 9 and $15 \mathrm{~km} \cdot \mathrm{h}^{-1}$ ) and a graded exercise running test (from $6 \mathrm{~km} \cdot \mathrm{h}^{-1}$ until exhaustion) on a treadmill. Physiological $\left(\mathrm{VO}_{2 \mathrm{max}}\right.$, heart rate, running economy, peak speed...) and biomechanical variables (contact and flight times, step rate and length) were simultaneously registered. Trained runners showed higher step rate and shorter step length than the Untrained group at the same running speeds (between $4-7 \%, \mathrm{p}<0.05$ ) and at the same physiological intensities (between $7-11 \%$, $\mathrm{p}<0.05)$. However, there were no differences in contact and flight times between groups. Significant differences $(\mathrm{p}<0.05)$ and large effect sizes (Cohen's $d$ ) between groups were found for body mass, sum of 6 skinfolds, $\mathrm{VO}_{2 \max }$, peak speed, ventilatory threshold and respiratory compensation threshold speeds. The Trained group also showed a $\sim 7 \%$ better running economy $\left(\mathrm{ml} \cdot \mathrm{kg}^{-0.75} \cdot \mathrm{km}^{-1}\right)$ than the Untrained group. In conclusion, adopting higher step rate and shorter step length may be an adaptive mechanism of the Trained group to reduce injury risk and possibly improve running economy. However, contact and flight times were consistent regardless of training level. 
Keywords: endurance running, biomechanics, physiology, injury risk, energy cost

\section{INTRODUCTION}

Long-distance running has increased in popularity in the last decade. According to the Running USA annual half-marathon report (32), since 2000, the number of finishers in halfmarathon races increased from 482,000 to $2,046,600$ in 2014 . This has led to great interest within the scientific community in studying different factors affecting both performance and injury risk in long-distance runners. The runners' physiological characteristics (i.e. $\mathrm{VO}_{2 \max }$, anaerobic threshold and running economy) and their influence on performance have been widely studied $(2,11)$. Additionally, some biomechanical variables such as leg stiffness and foot strike pattern have been shown to influence performance $(26,33)$. However, the relationship between the spatio-temporal parameters of running (i.e. step rate and length, contact and flight times) and both, performance and injury risk still remains unclear.

Previous studies have compared step rate and length in varying levels of trained runners $(6$, 31, 35). There are indications that experienced runners self-select higher step rates than novice ones $(6,10)$, which could an adaptation to optimize energy expenditure (18). De Ruiter et al. (10) observed that untrained individuals self-select a step rate $\sim 10 \%$ lower than that which would produce an optimal running economy (RE). Conversely, other authors have found that amateur marathon runners had a higher step rate and shorter step length than elite marathon runners at various standardized speeds (31). Only two studies analyzed the differences between trained runners and untrained individuals $(10,35)$, and their results were also contradictory. Moreover, several studies attempting to modify runners' preferred step rate and length showed decrements in $\operatorname{RE}(6,25,33)$. Some other studies tried to 
identify an optimal relationship between these variables and RE, without satisfactory results $(19,36,39)$.

The examination of the relationship between contact and flight times with RE yields similarly conflicting results. Some studies argue that for a given running speed, increased contact time is related to a better RE and performance, because a higher contact time implies a lower ground reaction force, which explains between $70-90 \%$ of energy cost of running $(13,15)$. Conversely, others associated a lower contact time with a better performance $(15$, 30), possibly because running speeds and foot strike patterns were not always wellcontrolled. To address this issue, it has been suggested that foot strike pattern and running speed be standardized when comparing running economy and spatio-temporal parameters of running between different level of runners and/or untrained individuals (29).

Modifications in step rate and length have also been associated with increased injury risk while running (34) likely due association with the magnitude and rate of impact force loading during the stance phase in some running injuries (23). Research suggests that increased step rate, and subsequent reduction in step length, decreases the magnitude of several key biomechanical factors associated with running injuries (34), such as the center of mass vertical excursion, ground reaction force, impact shock, and may ameliorate energy absorption at the hip, knee, and ankle joints (34). Thus, increasing step rate during running has been commonly advocated as an injury prevention mechanism (34). Previous studies (7, 16, 34) have shown that the minimum change in step length required to observe biomechanical changes was $5 \%$, though an increase of around $10 \%$ was required step rate in step rate to elicit biomechanical differences (7, 16, 23, 34). Curiously, De Ruiter et al. (10) reported that trained runners had a step rate $\sim 9 \%$ higher than untrained participants. 
Taking into account the influence of spatio-temporal parameters of running on performance and injury risk, and the conflicting research relative to differences between trained runners and untrained individuals, the aim of this study was to compare the spatio-temporal parameters (i.e. contact and flight times, step rate and length) of trained long distance runners and untrained participants with the same foot strike pattern (rearfoot) during running at controlled speeds. Additionally, running economy was examined and compared between groups. It was hypothesized that step rate would be higher and step length shorter in trained runners compared to untrained participants, regardless of running speed. Conversely, no differences in either contact or flight times at the same absolute velocities were expected between groups based on the standardized rearfoot strike pattern among participants.

\section{METHODS}

\section{Experimental Approach to the Problem}

Spatio-temporal parameters of running (i.e. step rate and length, contact and flight times) and physiological variables $\left(\mathrm{VO}_{2 m a x}\right.$, ventilatory threshold, respiratory compensation threshold and RE) among trained runners and untrained participants with the same foot strike pattern (i.e. rearfoot strikers) were compared in the present study. Submaximal running test and graded exercise were performed allowing comparison of biomechanical and physiologic parameters between groups at standard speeds and at the same physiological intensities. 


\section{Subjects}

Twenty-one participants took part in the present study. They were divided into two groups according to their training experience: Untrained group were 11 healthy non-trained participants (age: $25.6 \pm 4.8$ years; height: $176.7 \pm 5.3 \mathrm{~cm} ; \Sigma 6$ skinfolds: $61.5 \pm 25.4 \mathrm{~mm}$; body mass: $73.2 \pm 6.3 \mathrm{~kg}$; body mass index: $23.4 \pm 2.1 \mathrm{~kg} \cdot \mathrm{m}^{-2}$ ) who performed 2-3 days per week of moderate physical activity, but not specific running training. The trained groups consisted of 10 amateur runners with at least two years of training experience in long distance running, a training frequency of at least 3 days per week and a personal best time on a half marathon between 1:10:00 and 1:26:00 hh:mm:ss (age: $26.6 \pm 6.6$ years; height: $174.7 \pm 4.9 \mathrm{~cm} ; \Sigma 6$ skinfolds: $41.0 \pm 9.3 \mathrm{~mm}$; body mass: $65.9 \pm 4.2 \mathrm{~kg}$; body mass index: $21.6 \pm 1.0 \mathrm{~kg} \cdot \mathrm{m}^{-2}$ : weekly training volume: $57.5 \pm 22.6 \mathrm{~km}$ ). None of them were involved in strength training programs at the time of participation in the study. The protocol was approved by the University Ethics Committee, in accordance with the Declaration of Helsinki for human research. All participants signed a written informed consent to participate in the study and were informed of the objectives, procedures, benefits, and possible risks involved in the study.

The foot strike pattern was considered as an inclusion criteria for both groups, because it has been shown that this variable affects contact and flight times (29). All of the participants were rearfoot strikers, which is the most common foot strike pattern in long distance runners $(15)$. 


\section{Procedures}

All the participants were evaluated during the same period of the year (May-June) in a single data collection session. First, their anthropometric characteristics and the weight of their shoes were collected. After this, they performed 10 min of running warm-up on a treadmill at $\sim 10 \mathrm{~km} \cdot \mathrm{h}^{-1}$, followed by $5 \mathrm{~min}$ of free stretching of the lower limbs. Second, a submaximal running test followed by a graded exercise test were performed with 25 -min rest in-between. All testing sessions were conducted at the same time of day (between 10 a.m. and 1 p.m.), under similar environmental conditions ( $\sim 600 \mathrm{~m}$ altitude, $20-24^{\circ} \mathrm{C}$ and $45-$ $55 \%$ relative humidity). All subjects were instructed on proper hydration and carbohydrate intake prior to testing (21) and they were instructed to not perform hard training in the 48 hours prior to testing.

All runners wore the same running shoes (250-300 $\mathrm{g}$ weight for each shoe) in both submaximal and graded tests to prevent this variable from affecting running economy (28, 29). Runners' body mass and height were recorded, together with six skinfold measurements (triceps, subscapular, suprailiac, abdominal, front thigh, and medial calf) using standard equipment (Harpender, CMS Instruments, London, UK). All measurements were made by the same researcher following the guidelines of the International Society for the Advancement of Kineanthropometry (27).

Running tests were performed on a calibrated treadmill (ERGelek EG2, Vitoria-Gasteiz, Spain) with a $1 \%$ of slope to mimic the effects of air resistance on the metabolic cost on a flat outdoor running track (21). In both running tests, respiratory gases were collected via open-circuit indirect calorimetry (Medisoft Ergocard, Medisoft Group, Sorinnes, Belgium) and HR was monitored (Polar RS800, Polar Electro Oy, Kempele, Finland). Equally, a contact laser platform, previously validated and used in other studies $(28,29)$, was installed 
in the treadmill to obtain the spatio-temporal parameters of running (SportJUMP System PRO, DSD Inc., León, Spain) allowing the analysis of contact and flight times, step rate and length during running. Spatio-temporal parameters were registered during the last $30 \mathrm{~s}$ of each stage to obtain at least 32-64 consecutive steps and thus reduce the effect of intraindividual step variability (3). To determine the runners' foot strike pattern a high-speed video camera recording at $600 \mathrm{~Hz}$ (Casio Exilim Pro EX-F1, Casio Europe GMBH, Norderstedt, Germany) was placed on the right side of the treadmill $(\sim 1 \mathrm{~m})$, perpendicular to the sagittal plane $(28,29)$. All runners were analyzed by the same researcher, who identified their foot strike pattern at speeds corresponding to the runners' race pace for the Trained Group $\left(15-18 \mathrm{~km} \cdot \mathrm{h}^{-1}\right)$ and for the Untrained Group $\left(12-14 \mathrm{~km} \cdot \mathrm{h}^{-1}\right)$. Only the runners who landed on the ground with the heel first (i.e. rearfoot strikers) were included for further analysis.

The submaximal test consisted on three running sets of 5-min with 5-min rest in-between. Untrained Group ran at 9, 11 and $13 \mathrm{~km} \cdot \mathrm{h}^{-1}$ and Trained Group ran at 11,13 and $15 \mathrm{~km} \cdot \mathrm{h}^{-1}$. $\mathrm{VO}_{2}$ and $\mathrm{HR}$ registry of the last 3-min of each set were considered as representative values and used for analysis (29). Running economy was determined as the $\mathrm{VO}_{2}$ cost at a given running speed expressed in $\mathrm{ml} \cdot \mathrm{kg}^{-1} \cdot \mathrm{min}^{-1}$ and $\mathrm{ml} \cdot \mathrm{kg}^{-0.75} \cdot \mathrm{min}^{-1}(4)$. As previously reported by Helgerud et al. (17), there is no difference between RE at velocities representing intensities between 60 and $90 \%$ of $\mathrm{VO}_{2 \max }$, therefore the better $\mathrm{RE}$ value between these intensities was chosen as representative value.

The graded exercise test started at $6 \mathrm{~km} \cdot \mathrm{h}^{-1}$ and increased $1 \mathrm{~km} \cdot \mathrm{h}^{-1}$ every $1 \mathrm{~min}$ until volitional exhaustion. Achievement of $\mathrm{VO}_{2 \max }$ was determined based on the attainment of at least two of the following three criteria: a plateau in $\mathrm{VO}_{2}$ with increasing speeds; a respiratory exchange ratio above 1.15; participants reaching their age-predicted maximal 
heart rate (220-age) (12). The ventilatory threshold (VT) and the respiratory compensation threshold (RCT) were identified according to the criteria of Davis (9). The $\mathrm{VO}_{2 \max } / \mathrm{RE}$ ratio was calculated as the quotient between $\mathrm{VO}_{2 \max }$ and $\mathrm{RE}$, both expressed in $\mathrm{ml} \cdot \mathrm{kg}^{-1} \cdot \mathrm{min}^{-1}(19$, 36, 39). Biomechanical parameters were recorded during each stage above $10 \mathrm{~km} \cdot \mathrm{h}^{-1}$ to ensure that all subjects were running (identified by the presence of flight time) $(28,29)$.

\section{Statistical Analysis}

All values are expressed as mean \pm standard deviation (SD), and in some variables $95 \%$ confidence intervals $(95 \% \mathrm{CI})$ were also calculated. The Kolmogorov-Smirnov test was applied to ensure a normal distribution of all results. A one-way ANOVA was used to analyze the differences between both groups. The magnitude of differences or effect sizes (ES) were calculated according to Cohen's $d(8)$ and interpreted as small $(0.2 \leq \mathrm{ES}<0.5)$, moderate $(0.5 \leq \mathrm{ES}<0.8)$ and large $(\mathrm{ES} \geq 0.8)$. Intraclass correlation coefficient (ICC) was used to assess the validity of spatio-temporal parameters between both running tests (submaximal test and graded exercise test) at $11 \mathrm{~km} \cdot \mathrm{h}^{-1}$ and $13 \mathrm{~km} \cdot \mathrm{h}^{-1}$. The ICC was greater than or equal to 0.90 for all parameters (contact and flight time, step rate and length) at both speeds. SPSS version 23.0 statistical software (SPSS, Inc., Chicago, IL) was used. Values of $\mathrm{p}<0.05$ were considered statistically significant. 


\section{RESULTS}

Table 1 shows the participants' anthropometric characteristics and their physiological variables during the graded and submaximal tests. Significant differences $(p<0.05)$ and large effect sizes (ES) between groups were found for body mass, body mass index, sum of 6 skinfolds, $\mathrm{VO}_{2 \max }$, peak speed, VT speed, RCT speed, RE expressed in $\mathrm{ml} \cdot \mathrm{kg}^{-0.75} \cdot \mathrm{km}^{-1}$ and the quotient $\mathrm{VO}_{2 \max } / \mathrm{RE}$. No significant differences were found in $\mathrm{HR}_{\max }$, height and $\mathrm{RE}$ expressed in $\mathrm{ml} \cdot \mathrm{kg}^{-1} \cdot \mathrm{km}^{-1}$.

\section{\#Table 1 about here\#}

Table 2 shows the step rate and length of both groups during the graded exercise test. Overall (i.e. considering all the speeds), the Trained group showed $5.2 \pm 0.9 \%$ higher step rate than Untrained group $(2.94 \pm 0.1$ and $2.81 \pm 0.2 \mathrm{~Hz}$, respectively; $\mathrm{p}<0.05$ and $\mathrm{ES}=$ $0.97)$ and $5.6 \pm 1.2 \%$ shorter step length $(1.36 \pm 0.05$ and $1.46 \pm 0.09 \mathrm{~m}$, respectively; $\mathrm{p}<$ 0.05 and $\mathrm{ES}=1.37)$ than the Untrained group. Moderate to large effect sizes were observed for speeds from 10 to $17 \mathrm{~km} \cdot \mathrm{h}^{-1}$.

\section{\#Table 2 about here\#}

Figure 1 shows no significant differences between groups in contact and flight times during the graded exercise test. 


\section{\#Figure 1 about here\#}

Figure 2 shows significant differences $(\mathrm{p}<0.01)$ in step rate between both groups at similar physiological intensities. The Trained group used higher step rate at VT and RCT $(2.82 \pm$ $0.13 \mathrm{~Hz}, 95 \%$ CI $2.74-2.90 \mathrm{~Hz}$ and $3.01 \pm 0.12 \mathrm{~Hz}, 95 \%$ CI $2.94-3.07 \mathrm{~Hz}$, respectively) than Untrained group $(2.62 \pm 0.12 \mathrm{~Hz}, 95 \% \mathrm{CI} 2.55-2.70 \mathrm{~Hz}$ and $2.75 \pm 0,14 \mathrm{~Hz}, 95 \% \mathrm{CI}$ $2.66-2.85 \mathrm{~Hz}$, respectively).

\#Figure 2 about here\#

\section{DISCUSSION}

The main outcome of the present study was that trained runners demonstrated a higher step rate and shorter step length (between 4-7\%) than untrained participants at all running speeds above $10 \mathrm{~km} \cdot \mathrm{h}^{-1}$ (Table 2). These differences were more pronounced (between $7-11 \%$ ) at the same physiological intensities (Figure 2). This could be an adaptation to reduce loading at the hip and knee joints during running, which may be an adaptive mechanism to prevent some of the most common running-related injuries (16). Additionally, the present study demonstrated that when both foot strike pattern and velocity were controlled, contact and flight times were independent of running experience (Figure 1).

Only two previous studies analyzed the differences in step rate among trained and untrained participants (10). Slawinski \& Billat (35) observed that highly trained runners used a step rate $\sim 7-8 \%$ greater than well trained and untrained runners at the same running speed but that there were no differences between the latter two groups. Their findings conflict with the 
results of the present study (Table 2), possibly because their experiment was performed in the field (i.e. real conditions), and the ability to control speed (i.e. it was between $\sim 5-7 \%$ different among groups) and record a representative number of steps (i.e. only two steps were analyzed) was limited. Conversely, de Ruiter et al. (10) has reported that trained runners had a step rate $\sim 9 \%$ higher than untrained participants at the same physiological intensity ( $80 \%$ of RCT). These differences are similar to those reported in the present study (between 7-11\%) at different physiological intensities (Figure 2), demonstrating a clear preference in experienced runners to self-select higher step rates than untrained ones.

The higher step rate and shorter step length found in the experienced runners when compared to untrained participants could be associated with, among other factors, an adaptive mechanism to reduce injury risk by increasing step rate (35). Previous studies (16, 20) have observed that at a given running speed, a shorter step length decreases the impact of the foot on the ground, thereby reducing injury risk $(23,34)$. Considering the runningrelated injury rate among those who begin a running program (ranging from $19.4 \%$ to 79.3\%) (37), the findings of the present study, when viewed in context with previous research examining injury risk indicate that, some technical strategies could be adopted (i.e. cadence training with feedback) in an attempt to decrease injury risk and positively affect running economy (14)

The Trained and Untrained groups in the present study both exhibited a rearfoot strike pattern and demonstrated no differences in either the contact or flight times (Figure 2). These results disagree with previous research suggesting an association between shorter contact times and better performance $(15,30)$ or level of expertise $(10)$. However, not all previous research has controlled for factors that may effect this association. Due to the effect of foot strike pattern and running speed on contact and flight times, both variables 
were controlled in the present study, as in some previous studies $(28,29)$. Additionally, at running speeds of 12,14 and $16 \mathrm{~km} \cdot \mathrm{h}^{-1}$, contact times $(0.276 \pm 0.017,0.249 \pm 0.014$ and $0.228 \pm 0.013 \mathrm{~s}$, respectively) were similar to those reported $(0.278 \pm 0.017,0.252 \pm 0.014$ and $0.230 \pm 0.011 \mathrm{~s}$, respectively) in a previous study which involved highly trained runners with a rearfoot strike pattern (half marathon time lower than 1:15:00 hh:mm:ss) (29). These results suggest that for the same submaximal running speed, contact and flight times do not seem to vary with the level of training or running experience. In other words, at submaximal speeds, timing is very consistent in humans while running. This new finding warrants further investigation (i.e. neural mechanisms associated with this phenomenon).

In the present study, there were no significant differences in running economy between trained runners and untrained participants if this variable was expressed in $\mathrm{ml} \cdot \mathrm{kg}^{-1} \cdot \mathrm{km}^{-1}$, and the contrary when it was expressed in $\mathrm{ml} \cdot \mathrm{kg}^{-0.75} \cdot \mathrm{km}^{-1}$ (Table 1). Since $\mathrm{VO}_{2}$ at a submaximal speed does not increase linearly in proportion to body mass, if the $\mathrm{VO}_{2}$ is expressed in $\mathrm{ml} \cdot \mathrm{kg}^{-}$ ${ }^{1} \cdot \mathrm{km}^{-1}$, lighter runners may be classified as less efficient than heavier runners (4). Given the differences in mass between the two groups, and following the recommendations of Bergh et al. (4), it could be assumed that running economy expressed in $\mathrm{ml} \cdot \mathrm{kg}^{-0.75} \cdot \mathrm{km}^{-1}$ more accurately reflects the differences between groups. Several studies associated running economy with running performance $(1,5,26,33)$, although in homogeneous groups of runners the effect size of this association has been questioned (24). The present study found that trained runners were between 5-7\% more economical than the untrained ones. These values are in line with the reduction in aerobic demand (6-7\%) observed between trained and untrained adults undergoing extended training programs $(38,39)$. Specifically, Morgan et al. (26) noted that sub-elite runners were 3\% more economical than moderately trained runners, and these were 9\% more economical than untrained. However, economical and 
uneconomical runners could be identified at all levels of performance $(22,26)$, and possibly between trained and untrained subjects.

Some limitations of the present study were: a- the analysis of treadmill running instead of track running. Although it can be assumed that kinematics and kinetics are very similar, instruments' accuracy and environmental conditions are better controlled in the laboratory (28); b- the differentiation between the effect of both running experience and step rate on running economy. Because of the collinearity of these variables, it is difficult to know the real effect of running experience on the other two variables. However, according to previous studies, running economy in untrained participants who increased step rate $\sim 9 \%$ only improved 1-2\% (9).

In conclusion, this study examined differences in spatio-temporal parameters between trained long distance runners and untrained participants which can be applied to benefit novice runners. Besides possessing a decreased physiological capacity (e.g. lower $\mathrm{VO}_{2 \max }$ and running economy, higher percent body fat), untrained runners also demonstrated lower step rate and longer step length compared to trained runners at the same running speeds (between 4-7\%) and at the same physiological intensities (between 7-11\%). These differences may represent an adaptive mechanism to reduce the injury risk while running that may be trained in novice runners to improve function and reduce injury risk. However, there were no differences in contact and flight times at the same submaximal speeds, showing a consistent timing for runners with the same foot strike pattern, independent of the level of training. The underlying mechanisms for this similarity between runners of different training levels warrants further investigation. 


\section{PRACTICAL APPLICATIONS}

Since high step rate has been related to a decrease in running injuries, specific intervention, strategies and technical exercises employed by coaches to increase step rate of their runners may be advantageous. This is particularly important for novice runners given their tendency to use lower step rates at all speeds, but can also be applied for experienced runners, when this pattern is detected. According to the results of this study, step rate values in experienced runners should be near $2.82 \pm 0.13 \mathrm{~Hz}$ at VT (95\% CI 2.74-2.90 Hz) and 3.01士 $0.12 \mathrm{~Hz}$ at RCT (95\% CI 2.94-3.07 Hz). In this regard, step rate and length could be easily registered by means of portable and miniaturized sensors (e.g. Polar Sensor Running, Garmin HRM-Run, Suunto Foot POD, etc.) and compared with these reference values, which may help coaches and athletes monitor these parameters and determine their adequacy during training and competitions.

\section{REFERENCES}

1. Anderson, T. Biomechanics and running economy. Sports Medicine 22: 76-89, 1996.

2. Barnes, KR, and Kilding, AE. Strategies to improve running economy. Sports medicine 45: 37-56, 2015.

3. Belli, A, Lacour, JR, Komi, PV, Candau, R, and Denis, C. Mechanical step variability during treadmill running. European Journal of Applied Physiology and Occupational Physiology 70: 510-517, 1995.

4. Bergh, U, Sjodin, B, Forsberg, A, and Svedenhag, J. The relationship between bodymass and oxygen-uptake during running in humans. Medicine and Science in Sports and Exercise 23: 205-211, 1991. 
5. Bransford, DR, and Howley, ET. Oxygen cost of running in trained and untrained men and women. Medicine and Science in Sports and Exercise 9: 41-44, 1977.

6. Cavanagh, PR, and Williams, KR. The effect of stride length variation on oxygenuptake during distance running. Medicine and Science in Sports and Exercise 14: 30-35, 1982.

7. Clarke, TE, Cooper, LB, Hamill, CL, and Clark, DE. The effect of varied stride rate upon shank deceleration in running. Journal of Sports Sciences 3: 41-49, 1985.

8. Cohen, J. Statistical power analysis for the behavioral sciences. New York: Hillsdale, 1988.

9. Davis, JA. Anaerobic threshold - Review of the concept and directions for futureresearch. Medicine and Science in Sports and Exercise 17: 6-18, 1985.

10. de Ruiter, CJ, Verdijk, PW, Werker, W, Zuidema, MJ, and de Haan, A. Stride frequency in relation to oxygen consumption in experienced and novice runners. European Journal of Sport Science 14: 251-258, 2014.

11. Dellagrana, RA, Guglielmo, LGA, Santos, BV, Hernandez, SG, da Silva, SG, and de Campos, W. Physiological, anthropometric, strength, and muscle power characteristics correlates with running performance in young runners. Journal of Strength and Conditioning Research 29: 1584-1591, 2015.

12. Duncan, GE, Howley, ET, and Johnson, BN. Applicability of VO2max criteria: Discontinuous versus continuous protocols. Medicine and Science in Sports and Exercise 29: 273-278, 1997.

13. Gruber, AH, Umberger, BR, Braun, B, and Hamill, J. Economy and rate of carbohydrate oxidation during running with rearfoot and forefoot strike patterns. Journal of Applied Physiology 115: 194-201, 2013. 
14. Hafer, JF, Brown, AM, deMille, P, Hillstrom, HJ, and Garber, CE. The effect of a cadence retraining protocol on running biomechanics and efficiency: a pilot study. Journal of Sports Sciences 33: 724-731, 2015.

15. Hasegawa, H, Yamauchi, T, and Kraemew, WJ. Foot strike patterns of runners at the 15-km point during an elite-level half marathon. Journal of Strength and Conditioning Research 21: 888-893, 2007.

16. Heiderscheit, BC, Chumanov, ES, Michalski, MP, Wille, CM, and Ryan, MB. Effects of Step Rate Manipulation on Joint Mechanics during Running. Medicine and Science in Sports and Exercise 43: 296-302, 2011.

17. Helgerud, J, Støren, $\varnothing$, and Hoff, J. Are there differences in running economy at different velocities for well-trained distance runners? European Journal of Applied Physiology 108: 1099-1105, 2010.

18. Hunter, I, and Smith, GA. Preferred and optimal stride frequency, stiffness and economy: changes with fatigue during a 1-h high-intensity run. European Journal of Applied Physiology 100: 653-661, 2007.

19. Kyrolainen, H, Belli, A, and Komi, PV. Biomechanical factors affecting running economy. Medicine and Science in Sports and Exercise 33: 1330-1337, 2001.

20. Lenhart, RL, Thelen, DG, Wille, CM, Chumanov, ES, and Heiderscheit, BC. Increasing running step rate reduces patellofemoral joint forces. Med Sci Sports Exerc 46: $557-564,2014$

21. Lucia, A, Esteve-Lanao, J, Olivan, J, Gomez-Gallego, F, San Juan, AF, Santiago, C, Pérez, M, Chamorro-Viña, C, and Foster, C. Physiological characteristics of the best Eritrean runners - exceptional running economy. Applied Physiology, Nutrition, and Metabolism 31: 530-540, 2006. 
22. McGregor, SJ, Busa, MA, Yaggie, JA, and Bollt, EM. High resolution MEMS accelerometers to estimate $\mathrm{VO} 2$ and compare running mechanics between highly trained inter-collegiate and untrained runners. Plos One 4: e7355, 2009.

23. Mercer, JA, Devita, P, Derrick, TR, and Bates, BT. Individual effects of stride length and frequency on shock attenuation during running. Medicine and Science in Sports and Exercise 35: 307-313, 2003.

24. Mooses, M, Mooses, K, Haile, DW, Durussel, J, Kaasik, P, and Pitsiladis, YP. Dissociation between running economy and running performance in elite Kenyan distance runners. Journal of Sports Sciences 33: 136-144, 2015.

25. Morgan, D, Martin, P, Craib, M, Caruso, C, Clifton, R, and Hopewell, R. Effect of step length optimization on the aerobic demand of running. Journal of Applied Physiology 77: 245-251, 1994.

26. Morgan, DW, Bransford, DR, Costill, DL, Daniels, JT, Howley, ET, and Krahenbuhl, GS. Variation in the aerobic demand of running among trained and untrained subjects. Medicine and Science in Sports and Exercise 27: 404-409, 1995.

27. Norton, K, Whittingham, N, Carter, L, Kerr, D, Gore, C, and Marfell-Jones, M. Measurement techniques in anthropometry. In Anthropometrica. KNT, Olds, ed. Sydney: UNSW, 1996. pp. 25-75.

28. Ogueta-Alday, A, Morante, JC, Rodriguez-Marroyo, JA, and Garcia-Lopez, J. Validation of a new method to measure contact and flight times during treadmill running. Journal of Strength and Conditioning Research 27: 1455-1462, $2013 .$.

29. Ogueta-Alday, A, Rodríguez-Marroyo, JA, and García-López, J. Rearfoot striking runners are more economical than midfoot strikers. Medicine and Science in Sports and Exercise 46: 580-585, 2014. 
30. Paavolainen, LM, Nummela, AT, and Rusko, HK. Neuromuscular characteristics and muscle power as determinants of 5-km running performance. Medicine and Science in Sports and Exercise 31: 124-130, 1999.

31. Padulo, J, Annino, G, Migliaccio, GM, D'Ottavio, S, and Tihanyi, J. Kinematics of running at different slopes and speeds. Journal of Strength and Conditioning Research 26: 1331-1339, 2012.

32. Running USA. Annual half-marathon report http://www.runningusa.org/2015 [June 1, 2015]. Available from: http://www.runningusa.org/annual-reports.

33. Saunders, PU, Pyne, DB, Telford, RD, and Hawley, JA. Factors affecting running economy in trained distance runners. Sports Medicine 34: 465-485, 2004.

34. Schubert, AG, Kempf, J, and Heiderscheit, BC. Influence of stride frequency and length on running mechanics: a systematic review. Sports Health 6: 210-217, 2014.

35. Slawinski, JS, and Billat, VL. Difference in mechanical and energy cost between highly, well, and nontrained runners. Medicine and Science in Sports and Exercise 36: 14401446, 2004.

36. Støren, Ø, Helgerud, J, and Hoff J. Running stride peak forces inversely determine running economy in elite runners. Journal of Strength and Conditioning Research 25: 117$123,2011$.

37. van Gent, RN, Siem, D, van Middelkoop, M, van Os, AG, Bierma-Zeinstra, SMA, and Koes, BW. Incidence and determinants of lower extremity running injuries in long distance runners: a systematic review. British Journal of Sports Medicine 41: 469-480, 2007. 38. Wilcox, AR, and Bulbulian, R. Changes in running economy relative to VO2max during a cross-country season. Journal of Sports Medicine and Physical Fitness 24: 321326, 1984.

39. Williams, KR, and Cavanagh, PR. Relationship between distance running mechanics, running economy, and performance. Journal of Applied Physiology 63: 1236-1245, 1987. 


\section{Acknowledgements}

The authors thank the runners who participated in this study for their collaboration. This work was supported by the Basque Country Government under a predoctoral grant number reference PRE_2013_1_1109. The authors have no conflicts of interest to disclose, and the mention of the SportJump System Pro in this manuscript does not constitute endorsement by the National Strength and Conditioning Association.

\section{FIGURES CAPTIONS}

Figure 1. Contact (top marks) and flight times (bottom marks) of Trained and Untrained participants during the graded exercise test (from 10 to $17 \mathrm{~km} \cdot \mathrm{h}^{-1}$ ).

Figure 2. Step rate at ventilatory threshold (VT), respiratory compensation threshold (RCT) and peak speed for both groups (Trained vs Untrained). Significant differences between both groups: $* * \mathrm{p}<0.01 ; * * * \mathrm{p}<0.001$. 
Table 1. Anthropometric and physiological characteristics (means \pm SD) of trained and untrained participants.

\begin{tabular}{|c|c|c|c|c|}
\hline Variables & Trained $(n=10)$ & Untrained $(\mathrm{n}=11)$ & $\mathrm{p}$ & $\mathrm{ES}$ \\
\hline \multicolumn{5}{|l|}{ Anthropometric } \\
\hline Mass (kg) & $65.9 \pm 4.2 * *$ & $73.2 \pm 6.3$ & 0.006 & 1.37 \\
\hline Height $(\mathrm{cm})$ & $174.7 \pm 4.9$ & $176.7 \pm 5.3$ & 0.940 & - \\
\hline BMI $\left(\mathrm{kg} \cdot \mathrm{m}^{-2}\right)$ & $21.6 \pm 1.0^{*}$ & & 0.012 & 1.12 \\
\hline$\Sigma 6$ skinfolds $(\mathrm{mm})$ & $41.0 \pm 9.3^{*}$ & & 0.028 & 1.07 \\
\hline \multicolumn{5}{|l|}{ Graded test } \\
\hline $\mathrm{VO}_{2 \max }\left(\mathrm{ml} \cdot \mathrm{kg}^{-1} \cdot \mathrm{min}^{-1}\right)$ & $61.8 \pm 5.4 * *$ & $54.1 \pm 5.8$ & 0.006 & 1.38 \\
\hline $\mathrm{HR}_{\max }(\mathrm{bpm})$ & & $190.0 \pm 9.5$ & 0.274 & - \\
\hline Peak speed $\left(\mathrm{km} \cdot \mathrm{h}^{-1}\right)$ & & $16.5 \pm 1.2$ & 0.000 & 3.14 \\
\hline VT speed $\left(\mathrm{km} \cdot \mathrm{h}^{-1}\right)$ & & $9.4 \pm 0.9$ & 0.000 & 2.79 \\
\hline RCT speed $\left(\mathrm{km} \cdot \mathrm{h}^{-1}\right)$ & & $13.2 \pm 0.7$ & 0.000 & 3.16 \\
\hline \multicolumn{5}{|l|}{ Submaximal test } \\
\hline $\mathrm{RE}\left(\mathrm{ml} \cdot \mathrm{kg}^{-1} \cdot \mathrm{min}^{-1}\right)$ & $207.6 \pm 17.4$ & $217.6 \pm 13.9$ & 0.120 & - \\
\hline $\mathrm{RE}\left(\mathrm{ml} \cdot \mathrm{kg}^{-0.75} \cdot \mathrm{min}^{-1}\right)$ & $591.1 \pm 48.0^{*}$ & $635.5 \pm 36.0$ & 0.031 & 1.05 \\
\hline $\mathrm{VO}_{2 \max } / \mathrm{RE}\left(\min \cdot \mathrm{m}^{-1}\right)$ & $298.2 \pm 15.1^{* * *}$ & $248.4 \pm 20.2$ & 0.000 & 2.79 \\
\hline
\end{tabular}

BMI: body mass index; $\Sigma 6$ skinfolds: triceps, subscapular, abdominal, suprailiac, midthigh, and medial calf; $\mathrm{VO}_{2 \max }$ : maximum oxygen uptake rate; $\mathrm{HR}_{\max }$, maximum heart rate; Peak speed: maximal speed reached during the test; VT speed: speed at ventilatory threshold; RCT speed: speed at respiratory compensation threshold. RE, running economy. Significant differences between both groups: $* \mathrm{p}<0.05 ; * * \mathrm{p}<0.01$; ***p $<$ 0.001. ES: Effect size, Cohen's $d$ of the differences among groups. 
Table 2. Step rate and length (means $\pm S D)$ of Trained $(n=10)$ and Untrained participants $(n=11)$ during the graded exercise test (from 10 to $17 \mathrm{~km} \cdot \mathrm{h}^{-1}$ ).

\begin{tabular}{|c|c|c|c|c|c|c|c|c|}
\hline \multirow[b]{2}{*}{ Speed } & \multicolumn{4}{|c|}{ Step Rate $(\mathrm{Hz})$} & \multicolumn{4}{|c|}{ Step length (m) } \\
\hline & Trained & Untrained & $\mathrm{p}$ & $\mathrm{ES}$ & Trained & Untrained & $\mathrm{p}$ & $\mathrm{ES}$ \\
\hline $10 \mathrm{~km} \cdot \mathrm{h}^{-1}$ & $2.79 \pm 0.13^{*}$ & $2.67 \pm 0.14$ & 0.048 & 0.88 & $0.99 \pm 0.05^{*}$ & $1.04 \pm 0.05$ & 0.049 & 1.00 \\
\hline $11 \mathrm{~km} \cdot \mathrm{h}^{-1}$ & $2.82 \pm 0.11$ & $2.71 \pm 0.13$ & 0.057 & 0.91 & $1.08 \pm 0.04$ & $=0.05$ & 0.055 & 0.66 \\
\hline $12 \mathrm{~km} \cdot \mathrm{h}^{-1}$ & $2.86 \pm 0.11^{*}$ & $2.73 \pm 0.14$ & 0.036 & 1.03 & & & 0.037 & 1.08 \\
\hline $13 \mathrm{~km} \cdot \mathrm{h}^{-1}$ & $2.91 \pm 0.10 *$ & $2.76 \pm 0.15$ & 0.021 & 1.17 & & & 0.021 & 1.22 \\
\hline $14 \mathrm{~km} \cdot \mathrm{h}^{-1}$ & $2.95 \pm 0.09 *$ & $2.79 \pm 0.14$ & 0.011 & 1.35 & & $1.40 \pm 0.07$ & 0.012 & 1.40 \\
\hline $15 \mathrm{~km} \cdot \mathrm{h}^{-1}$ & $2.99 \pm 0.08 * *$ & $2.82 \pm 0.15$ & 0.008 & 1.41 & & $1.47 \pm 0.08$ & 0.009 & 1.26 \\
\hline $16 \mathrm{~km} \cdot \mathrm{h}^{-1}$ & $3.05 \pm 0.09 * *$ & $2.85 \pm 0.15 \#$ & 0.005 & & $1.45 \pm 0.04 * *$ & $1.56 \pm 0.09 \#$ & 0.006 & 1.57 \\
\hline $17 \mathrm{~km} \cdot \mathrm{h}^{-1}$ & $3.10 \pm 0.11^{* *}$ & $2.98 \pm 0.17 \$$ & 0.001 & & $1.52 \pm 0.05^{* *}$ & $1.58 \pm 0.09 \$$ & 0.001 & 0.82 \\
\hline
\end{tabular}

Significant differences between both groups: ${ }^{*} \mathrm{p}<0.05 ; * \mathrm{*}<<0.01$. Number of untrained runners in this stages: $n=9(\#)$ and $n=7$ (\$). ES: Effect size, Cohen's $d$ of the differences among groups. 


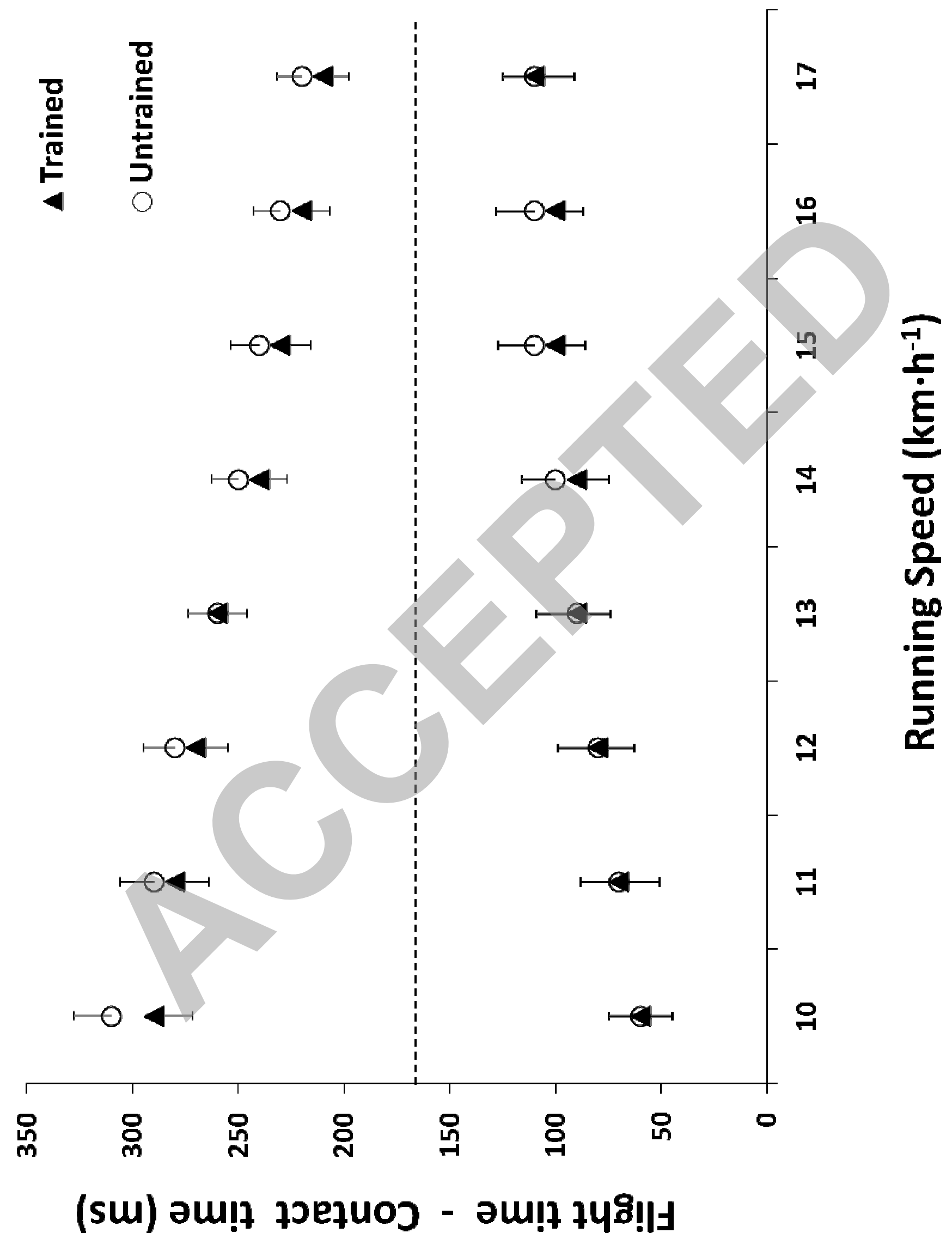




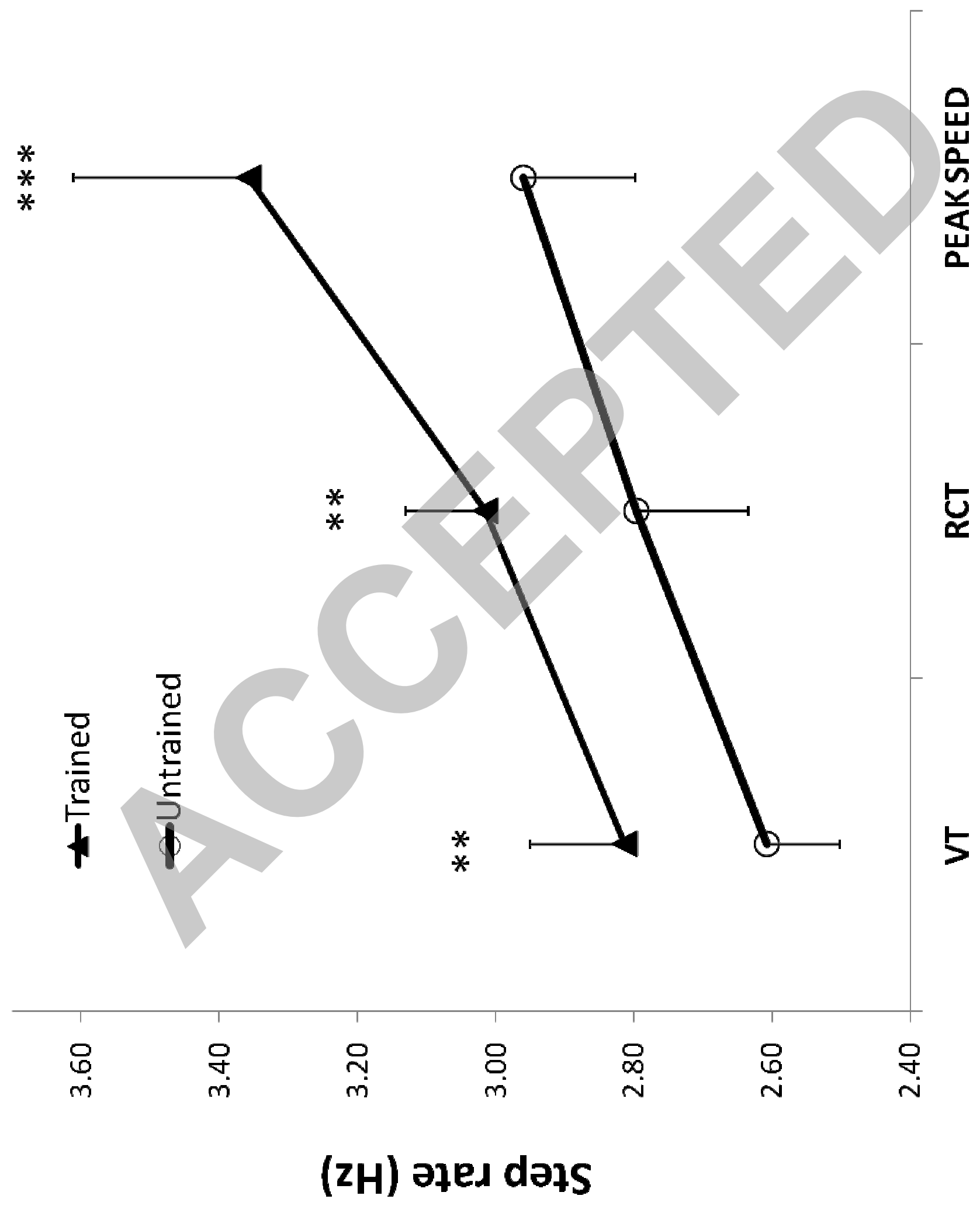

